\title{
DESIGN AND OPTIMIZATION OF POWERTRAIN SYSTEM FOR PROTOTYPE FUEL CELL ELECTRIC VEHICLE
}

\author{
S.M.H.S. Omar ${ }^{1}$, N.M. Arshad ${ }^{1}$, I.M. Yassin ${ }^{1}$, M.H.A.M. Fakharuzi ${ }^{2}$ and \\ T.A. Ward ${ }^{3}$ \\ ${ }^{\mathbf{1}}$ Faculty of Electrical Engineering, MARA University of Technology (UiTM), \\ 40450 Shah Alam, Selangor, Malaysia \\ Phone: +6017-4425411 \\ Email: syedmharussani@yahoo.com \\ Email:nhash2@gmail.com \\ Email: ihsan.yassin@gmail.com \\ ${ }^{2}$ Faculty of Mechanical Engineering, MARA University of Technology (UiTM), \\ 40450 Shah Alam, Selangor, Malaysia. \\ Email: fettermes@hotmail.com \\ ${ }^{3}$ Department of Mechanical Engineering, Faculty of Engineering Building, University \\ of Malaya, 50603 Kuala Lumpur, Malaysia. \\ Email: drtomward@um.edu.my
}

\begin{abstract}
This paper reports the analysis of an automatic intelligent controller for driving a prototype fuel cell electric vehicle over different obstacles while maintaining all systems at maximum efficiency during completion of a race within a specified time. The objective is to reduce driving errors, such as excessive driving, or over revving the throttle while controlling the energy usage at the minimum point and improving driving skills for the Shell Eco-marathon Asia 2014 race. The vehicle is equipped with a proton exchange membrane (PEM) fuel cell system, a brush DC motor and a DC/DC converter. This prototype vehicle is a single-seater type of car and has a streamlined body shape that is designed for energy-efficiency racing where the objective is to achieve the furthest distance with the least amount of fuel in a specified time. In the design process, the car's fuel-cell efficiency, energy demand, track behavior, motor efficiency analysis, and driving control strategy need to be monitored and used to verify the designed automated intelligent controller. Experiments on the automated intelligent controller were undertaken to analyze the performance of the powertrain system for a certain given time. This powertrain system for automated intelligent controller analysis is part of the energy efficiency study of the electric vehicle. It forms the knowledge base for the next detailed energy efficiency analysis.
\end{abstract}

Keywords: powertrain system; automatic intelligent controller; fuel cell efficiency; brush DC motor efficiency; driving strategy; Shell eco-marathon

\section{INTRODUCTION}

Energy and pollution are becoming the biggest problems around the world. The crisis of the energy consumption of the human population in daily life is increasing and, when talking about the energy of a transportation vehicle, most of the world uses fossil fuel to generate power. Energy is one of the concerns of the engineers who are trying to work 
out how to generate power using several techniques and applications. As a consequence, novel renewable and clean energy power sources must be considered. One of the prevalent alternative sources of electric power is the fuel cell [1-5]. For many years now, FCs, and more especially proton exchange membrane (PEM) FCs, have been considered to be very promising long-term replacements for the conventional internal combustion engine in automobile applications [6]. The proton exchange membrane fuel cell (PEMFC) is a renewable energy device which, by electrochemically generated DC power, converts the chemical reaction of gasses to electric energy as the power source for an electric vehicle. In future, automobiles will have to move away from the conventional gasoline-based internal combustion engine due to depleting fossil fuel reserves [2].

Research into FC development, performance and hybridization with application to vehicles has been taken seriously by many institutions, especially automotive producers $[7,8]$. The categories of the FC vehicles which have been developed are not limited, therefore many sectors are involved including public transportation $[9,10]$ military [11] and recreation [12-14]. FCs have no advantages over the internal combustion engine at full load. FC system efficiency drops sharply at low power output because of the balance of components, such as blowers and auxiliary systems (FC controllers, DC/DC converters, motors, motor controllers etc.). To overcome the problem, optimization of the powertrain of the FC needs to be undertaken first to allow the FC system to operate more efficiently. The principle of the Shell Eco-marathon Asia 2014 competition is an energy-efficiency race and is actually very simple but challenging. Students need to customize a single-seater vehicle to achieve the highest possible fuel efficiency in driving a vehicle the furthest with the lowest amount of fuel at a minimum average speed $(30 \mathrm{~km} / \mathrm{h})$. This paper reports the methodology that was followed by our team to design an FC powertrain in order to participate in the most prestigious energy-efficiency race, the Shell Eco-marathon Asia, in 2014. Reaching this objective involves the following challenges:

- The nominal power used for this prototype vehicle is below $1 \mathrm{~kW}$. As an FC is used as the power source, the operation of the FC system at maximum efficiency needs to be studied to indicate the efficiency range since different loads will result in different efficiencies. Energy losses from the auxiliary system can be identified and can lead us to operate the FC system at maximum efficiency while designing an intelligent control system.

- Powertrain system design mainly contributes to the efficiency of vehicles. The leading parameter is not the power to be supplied, as is generally the case in FC powertrain design $[12,15,16]$. In the race, the constraint is to travel the Luneta Park track: $1.2 \mathrm{~km}$ per lap, for 10 laps $(12 \mathrm{~km})$ to finish the race within $24 \mathrm{~min}$ (average speed $=30 \mathrm{~km} / \mathrm{h}$ ). The energy demand can be calculated based on the road track behavior of the Luneta Park track. The results must be analyzed to assess the lowest energy consumption.

- The type of driving technique also needs to be understood since there is no need to accelerate each time. The fixed amplitude speed range and constant speed need to be studied. By conducting a fixed amplitude speed range experiment, the vehicle can freewheel and perhaps save much energy. Hence, energy management throughout the race is an important issue to be addressed. 


\section{METHODOLOGY}

\section{PEMFC Efficiency Test}

As a starting point, it should be recalled that FCs offer many advantages, such as high efficiency and high power density, but also have some drawbacks, such as high sensitivity to load variations [10] Considering motor efficiency of 93\%, the FC stack nominal power has to be around $50 \mathrm{~W}$. The FC stack must supply this electric power with the highest efficiency. In a first approximation, the stack efficiency is directly related to the stack voltage by the following relation:

$$
\eta_{\text {Stack }}=\frac{v \cdot i}{m H_{2} \cdot L H V \frac{m}{H_{2}}}=\frac{F}{\eta \cdot L H V \frac{m}{H_{2}}}
$$

where $L H V \frac{m}{H_{2}}$ is the lower heating value of $H_{2}$ in mass, $V$ is the stack voltage, $I$ is the stack current, $\mathrm{mH}_{2}$ is the mass hydrogen flow rate, $F$ is the Faraday constant and $n$ is the cell number. This relation indicates that the higher the stack voltage, the higher the efficiency. However, stack efficiency falls at very low power even when it is in the region where the stack voltage is the highest. The $1 \mathrm{~kW}-\mathrm{FC}$ produced by Horizon FC was chosen. The H-1000XP FC stack is a cathode-cooled PEMFC stack designed to provide stable electrical power while operating on air and dry hydrogen [17]. With innovative materials, the H-1000XP achieved a $1000-\mathrm{W}$ power output with less weight and a more compact size.

The nominal stack power is $1100 \mathrm{~W}$ while only $137 \mathrm{~W}$ (based on the total power required in Table 1 is typically needed to power the car. Thus, the stack efficiency is high and little heat is generated. In the choice of the appropriate PEMFC stack, an important parameter was taken into account, the output stack voltage. Experiments on fuel efficiency were conducted to ensure the efficiency of the FC for each load demand. Since FC efficiency is different for each load, in the experiment the load was increased from $50 \mathrm{~W}, 100 \mathrm{~W}, 150 \mathrm{~W}$ to $1000 \mathrm{~W}$ as shown in Figure 1.

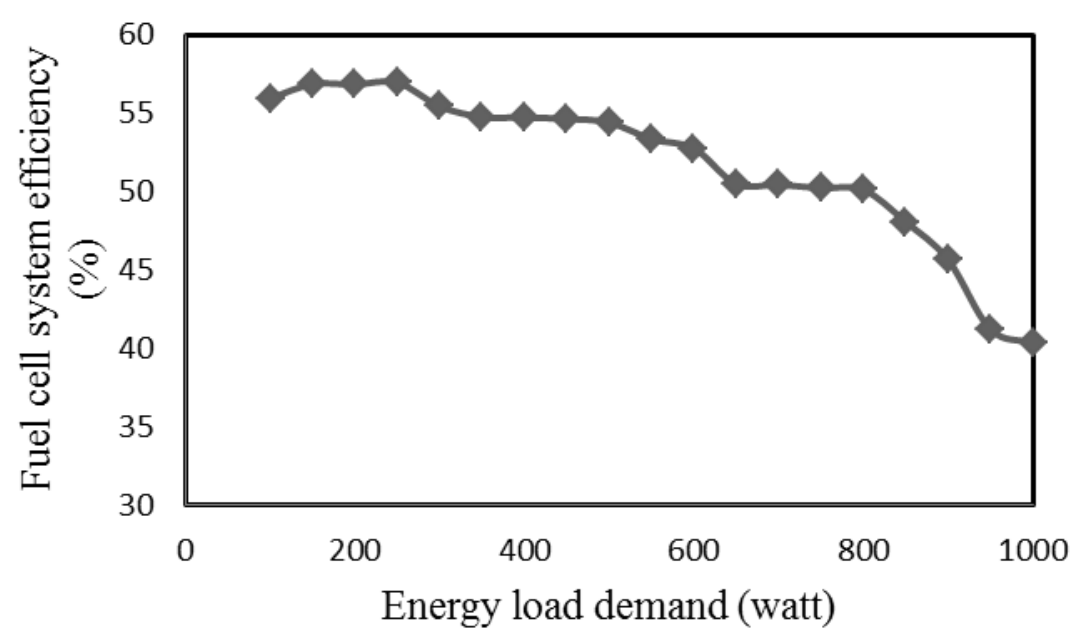

Figure 1. Efficiency curve for PEMFC Horizon 1000XP. 
Table 1. Total power needed for a speed of $30 \mathrm{~km} / \mathrm{h}$.

\begin{tabular}{ccccccc}
\hline $\begin{array}{c}\text { Speed } \\
(\mathrm{km} / \mathrm{h})\end{array}$ & $\begin{array}{c}\mathrm{P}_{\text {grad }} \\
(\mathrm{W})\end{array}$ & $\begin{array}{c}\mathrm{P}_{\text {ma }} \\
(\mathrm{W})\end{array}$ & $\begin{array}{c}\mathrm{P}_{\text {aero }} \\
(\mathrm{W})\end{array}$ & $\begin{array}{c}\mathrm{P}_{\text {roll }} \\
(\mathrm{W})\end{array}$ & $\begin{array}{c}\mathrm{P}_{\text {Total }} \\
(\mathrm{W})\end{array}$ & $\begin{array}{c}\mathrm{P} \text { Total } \\
(\mathrm{Nm})\end{array}$ \\
\hline $30 \mathrm{~km} / \mathrm{h}$ & 0 & 51.56 & 65.10 & 20.03 & 136.69 & 3.98 \\
\hline
\end{tabular}

Based on the experiment conducted, FC efficiency is different for each load demand. High efficiency was achieved at a load demand of $150 \mathrm{~W}$ and also for other load demands, such as at 100, 200, 250 and $300 \mathrm{~W}$. From this experiment, the user can ascertain which load demand (motor) needs to operate to maintain the FC efficiency at as high a level as possible. At the 1000-W load the FC efficiency was lower than under the others. Operating the system under this condition was the worst condition since it has low efficiency. Based on the results obtained from the experiment, the energy load demand to move the car to maintain the FC efficiency can be ascertained at as high a level as possible. The design of the powertrain system needs to follow these results to maintain the $\mathrm{FC}$ at maximum efficiency.

\section{Vehicle Dynamics Modeling (Energy Demand)}

This is an important part of designing a vehicle whereby all sources of force are considered in optimizing the energy consumption of a light-weight vehicle. The gearing ratio can be determined from the related formula. All forces are shown in Figure 2.

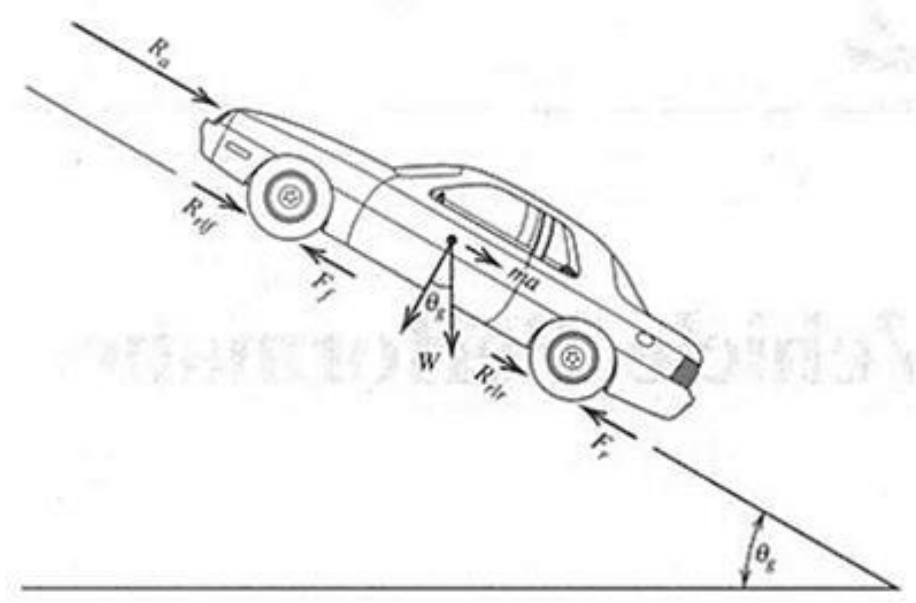

Figure 2. Forces act on the vehicle due to the track inclination condition.

In moving the vehicle, the engine has to develop sufficient power to overcome the road resistance power, and, to move the vehicle from a standstill or to accelerate, reverse power in addition to that absorbed by the road resistance must be available when required. Road resistance is expressed as tractive resistance. The propelling thrust at the tire to road interface needed to overcome this resistance is known as tractive effort, $F_{t e}$ (Nm) [18]. Equation 2 shows the forces that act to move the vehicle from a standstill.

$$
F_{t e}=F_{l a}+F_{a d}+F_{r r}+F_{h c}+F_{\omega a}
$$


where;

$F_{l a}=$ is the force required to give linear acceleration.

$F_{a d}=$ is the force due to the friction of the vehicle body moving through the air.

$F_{r r}=$ is the force due to friction of the vehicle tire on the road (rolling resistance).

$F_{h c}=$ is the force due to climbing the hill.

$F_{\omega a}=$ is the force required to give angular acceleration to the rotating motor.

The elements of all forces without accounting for hill climbing force are equivalent to:

$$
\frac{G}{r} \eta T=\mu_{r r} m g+0.625 A C_{d} v^{2}+\left(m+\frac{I G^{2}}{\eta_{G} r^{2}}\right) \frac{d v}{d t}
$$

where $G$ is a gear ratio, $r$ is wheel radius, $\mu_{\mathrm{rr}}$ is rolling coefficient, $A$ is vehicle frontal area, $C_{d}$ is drag coefficient, $m$ is vehicle mass, $I G^{2} / \eta_{G} r^{2}$ is an angular acceleration mass factor normally determined as $5 \%$ of vehicle mass [17], $\eta$ is gear efficiency, $d v / d t$ is acceleration, and $T$ is torque.

\section{Road Track Behavior}

Figure 3 shows the Luneta Park track layout. Based on the total distance and total laps needed to be completed in under the 24 min time given, the average speed is $30 \mathrm{~km} / \mathrm{h}$. However, since the track has a $90^{\circ}$ bend at each corner, the cars need to slow down for every turn. Several factors should be considered in finding the optimum speed for the vehicle, such as slowing down if there is an accident in front, the vehicle in front slows down due to system failure etc. It is very important to make sure that the vehicle runs at maximum efficiency while still finishing the race within the specified time.

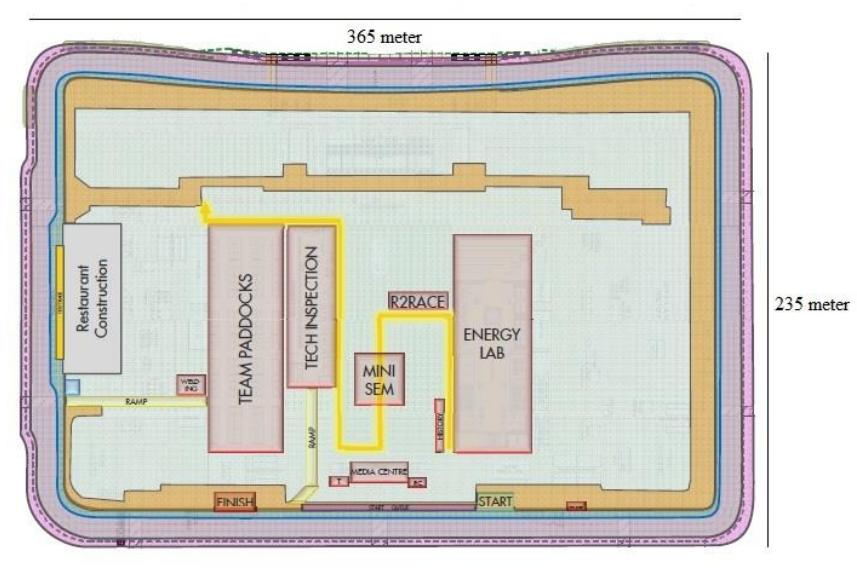

Figure 3. Track layout Luneta Park, Manila.

Since the vehicle run is almost a flat road, climbing forces due to hills can be ignored. First, the vehicle parameters need to be obtained to ascertain the important characteristics of the vehicle for analysis. Table 2 shows the vehicle dynamics parameters. From the vehicle dynamics parameters, the power needed to achieve the target speed can be obtained. Table 1 shows the power needed for the vehicle to achieve a speed of $30 \mathrm{~km} / \mathrm{h}$. 
Table 2. Vehicle dynamics parameters.

\begin{tabular}{lccc}
\hline Vehicle Dynamics Parameters & Values & $\begin{array}{c}\text { Vehicle Dynamics } \\
\text { Parameters }\end{array}$ & Values \\
\hline Vehicle mass + driver & $98 \mathrm{~kg}$ & Drag reference area & $0.5 \mathrm{~m}^{2}$ \\
Angular acceleration mass factor & $4.5 \mathrm{~kg}$ & Coefficient of drag & 0.20 \\
Rolling resistance coefficient & 0.0025 & Wheel radius & $0.24 \mathrm{~m}$ \\
\hline
\end{tabular}

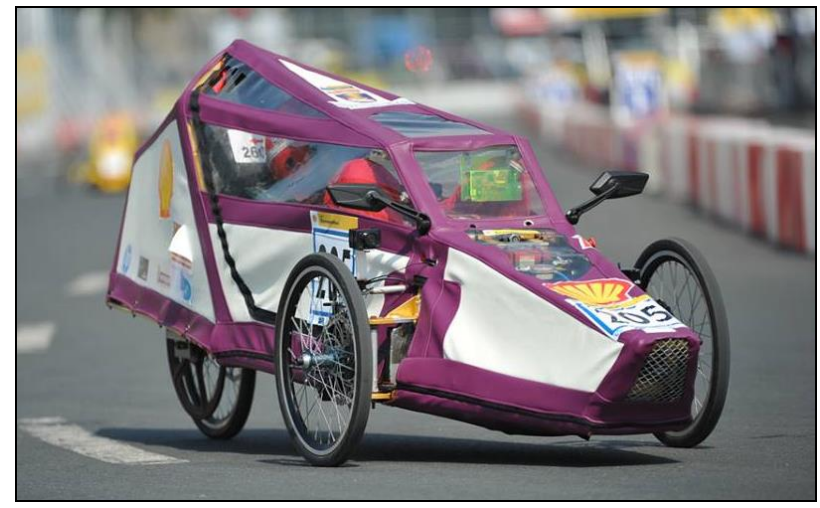

Figure 4. SperMotive-2 on the track at Luneta Park, Manila.

The total power needed to achieve a speed of $30 \mathrm{~km} / \mathrm{h}$ is $136.69 \approx 137 \mathrm{~W}$ but the vehicle needs to travel at least around $1100 \mathrm{~m}$ (around $2.2 \mathrm{~min}$ ) before achieving this speed. Linear acceleration force relates to acceleration from starting until reaching 30 $\mathrm{km} / \mathrm{h}$ within a specific distance. Acceleration from a standstill to $30 \mathrm{~km} / \mathrm{h}$ can be faster but the force will increase and affect the efficiency of the motor. Since acceleration takes so much time, the speed range in which the efficiency of the system will be kept high will be calculated in selecting the electric motor.

\section{Direct Current (DC) Motor Characteristics}

In modeling vehicle acceleration, motor torque should be identified. Torque is directly proportional to the current and the relationship between torque and current is as in Equations (4), (5) and (6) where $I$ is armature current, $V_{s}$ is terminal voltage, $R_{a}$ is armature resistance, $K_{m}$ is torque constant, $\omega$ is motor speed, and $T_{f}$ is torque friction [14] The consideration of torque friction in the torque equation will give more modeling accuracy [19].

$$
\begin{gathered}
I=\frac{V_{s}}{R_{a}}-\frac{K_{m}}{R_{a}} \omega \\
T=I K_{m}-T_{f} \\
T=\left(\frac{V_{s}}{R_{a}}-\frac{K_{m}}{R_{a}} \omega\right) K_{m}-T_{f}
\end{gathered}
$$

The Maxon DC motor was chosen since its efficiency is $94 \%$ (high enough compared with other manufacturers of DC motors). Table 3 shows the motor parameters given by the manufacturer. However, for more accurate modeling results, the no-load 
current and no-load speed values must be taken from the actual test. Based on the data in Table 3, the efficiency curve can be modeled as shown in Figure 5. Based on this result, the region of maximum efficiency of the DC motor can be ascertained. This result needs to be considered in designing the automatic intelligent controller to ensure that the motor runs at its maximum efficiency. Based on this modeling, linear acceleration takes more time because, if acceleration to achieve the target speed of $30 \mathrm{~km} / \mathrm{h}$ takes a shorter time (24 seconds), the linear acceleration force increases to $283.56 \mathrm{~W}$ which, even though maximum efficiency of the FC is maintained, is beyond the region of maximum efficiency of the motor.

Table 3. DC motor parameters.

\begin{tabular}{l|c}
\hline DC motor parameters & Values \\
\hline Motor constant & $0.0604 \mathrm{Nm} / \mathrm{A}$ \\
Supply voltage & $36 \mathrm{~V}$ \\
Armature resistance & $0.244 \Omega$ \\
No-load speed & $5680 \mathrm{rpm}$ \\
No-load current & $0.147 \mathrm{~A}$ \\
\hline
\end{tabular}

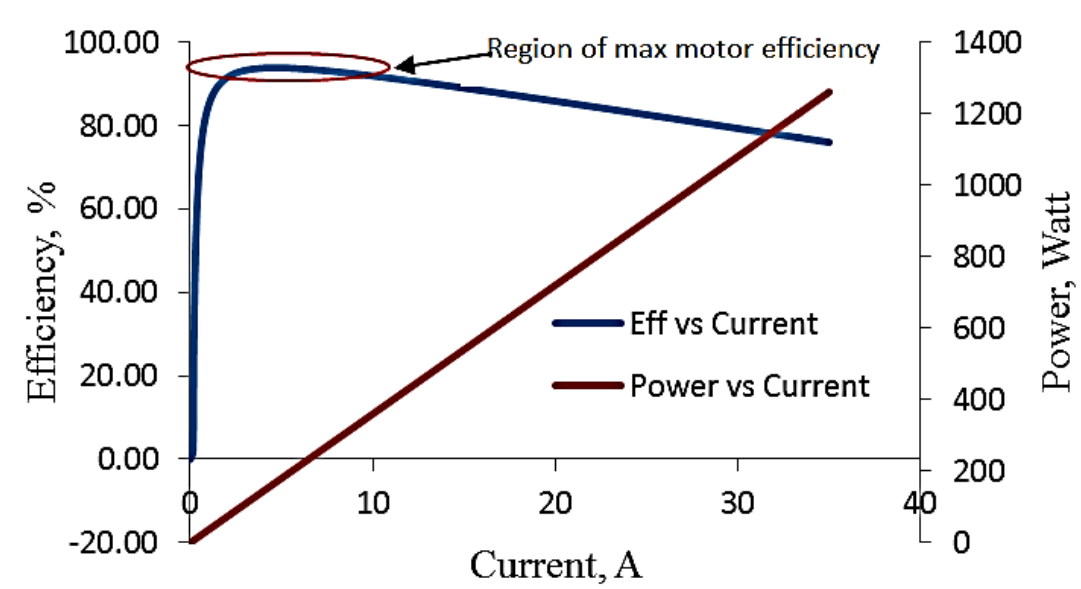

Figure 5. Modeling efficiency curve of Maxon DC motor.

\section{Energy-Efficient Driving Control Strategy}

Based on the analysis and the experiment conducted above, the data will be used to configure an energy-efficient driving control strategy for the vehicle. In designing the controller, the powertrain configuration needs to be setup first to identify a suitable method of control (current or voltage). To respect the race rules, no battery other than an auxiliary is allowed in the powertrain system. Thus, 2 kinds of FC powertrain structure can be considered [9]: the direct powertrain system, see Figure 6 (a), and the indirect power train system, see Figure 6 (b). Since the race does not require the vehicle to stop and start nor excessive braking, and is run on an almost flat road, the ultracapacitors can be removed from the designed powertrain system. Thus, the final powertrain comprises only the FC stack and controller, DC/DC buck converters and the DC electric motor. 


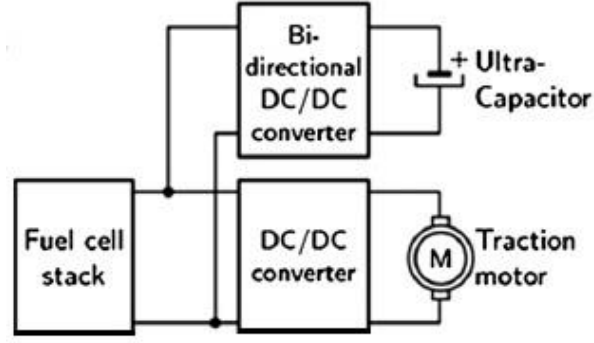

(a)

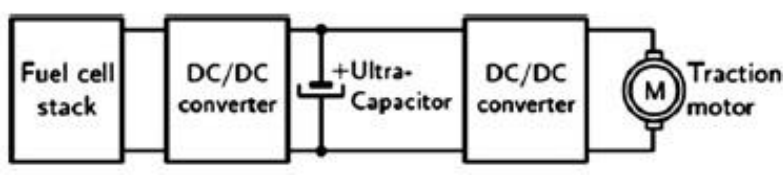

(b)

Figure 6. Powertrain FC system (a) direct (b) indirect.

Figure 7 shows the final configuration of the powertrain system. Based on that configuration, the DC/DC converter works in the current-control mode where the current is controlled at a target value which is fixed with a pre-calibrated potentiometer. The input from the potentiometer is used to accelerate and decelerate the vehicle and can also be used in designing the automated intelligent controller. After finalizing the configuration of the powertrain, the focus was then on an average car speed of $30 \mathrm{~km} / \mathrm{h}$. If a speed regulation strategy is used, the speed varies between a minimum and maximum value (centered about the average value) [20].

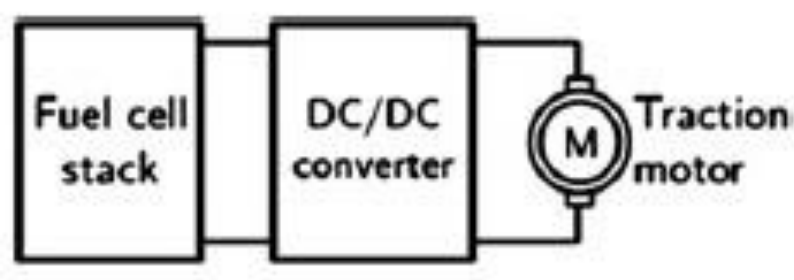

Figure 7. Configurations powertrain FC system.

Acceleration or deceleration between these 2 velocities is achieved with a constant wheel torque. Experiments were carried out into maintaining constant speed at $30 \mathrm{~km} / \mathrm{h}$ and for a fixed speed amplitude of around the target average value (25$35 \mathrm{~km} / \mathrm{h}$ ); the higher the wheel torque during acceleration, the shorter the acceleration and thus the higher the number of accelerations needed to complete the race [20]. An experiment was conduct to verify if the fixed speed amplitude or constant speed met our previous requirements. A study involving wider speed ranges was conducted (25$35 \mathrm{~km} / \mathrm{h}$ ) to determine the power usage from that speed range.

Based on that experiment, although more power was required during acceleration, the power usage while idling was almost zero, resulting in significant net power savings $(175 \mathrm{~W})$ while for a constant speed the power demanded was slightly higher $(198 \mathrm{~W})$ due to the higher power consumption since there is no idling time to maintain that constant speed. Figure 8 (a) presents data for the fixed speed amplitude $(25-35 \mathrm{~km} / \mathrm{h})$ and Figure 8 (b) presents data for the constant speed $(30 \mathrm{~km} / \mathrm{h})$. 


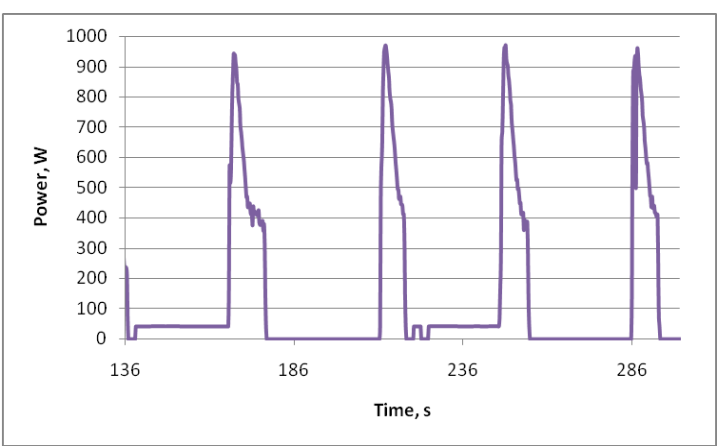

(a)

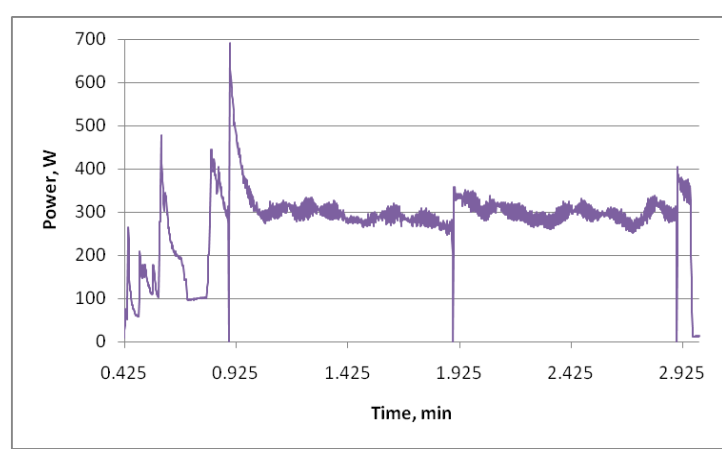

(b)

Figure 8 . Speed range (a) $25-35 \mathrm{~km} / \mathrm{h}$, (b) speed constant $30 \mathrm{~km} / \mathrm{h}$.

\section{Automated Intelligent Controller}

Usually, the driver controls the acceleration and deceleration manually by increasing and decreasing the throttle. With manual acceleration and deceleration, it is possible for the driver to over accelerate while driving. The general idea of an automated intelligent controller is that the driver just needs to press only one button and the system will then run automatically to the finishing line. Since acceleration takes a few seconds to achieve the target speed of $30 \mathrm{~km} / \mathrm{h}$, the system will automatically calculate the remaining distance and time. Based on that remaining distance and time, the system will run in an amplitude speed range to achieve race completion within the specified time. For example, after achieving the target speed, if the subsequent required speed is 24.90 $\mathrm{km} / \mathrm{h}$, the amplitude speed range is between $19.90 \mathrm{~km} / \mathrm{h}$ and $29.90 \mathrm{~km} / \mathrm{h}$ and, based on that speed range, the average is still around $24.90 \mathrm{~km} / \mathrm{h}$. The same techniques were also applied during braking due to an emergency and in cornering. All the systems will idle due to braking, and the controller will recalculate after the driver releases the brake paddle.

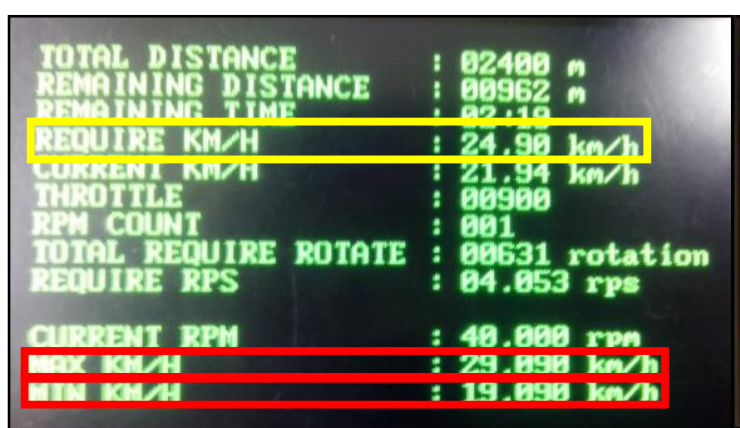

(a)

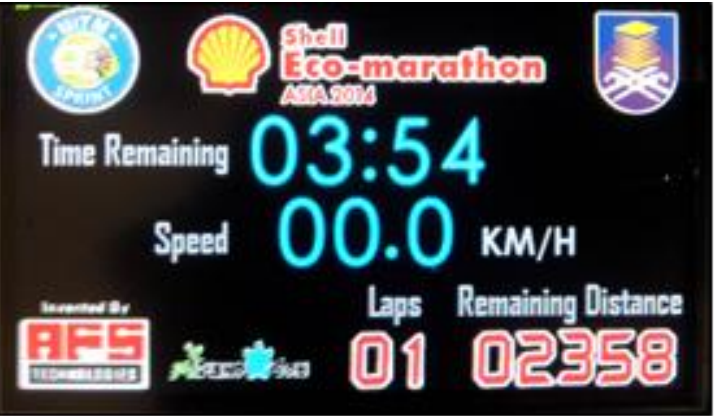

(b)

Figure 9. Displays for the automated intelligent controller.

Figure 9 (a) shows the display used for the calibration process. The red box indicates the average range amplitude for speed based on the required speed, while the required speed is shown in the yellow box. The required speed will change from time to time once the system has achieved the maximum amplitude of the speed range. Figure 9 (b) is the driver's display monitoring the system inside the vehicle. An experiment was conducted to verify whether the system will finish the race within a specified time both 
unhindered and with different types of obstacles. The structure of the experiment was that the vehicle needed to run $2400 \mathrm{~m}$ within $4.8 \mathrm{~min}(288 \mathrm{~s})$.

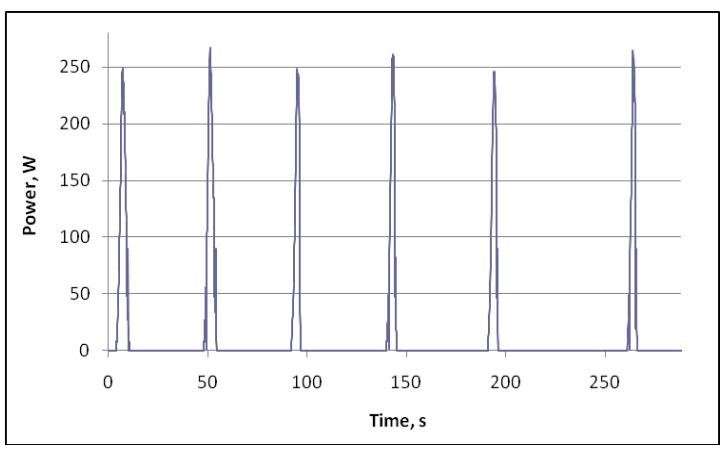

(a)

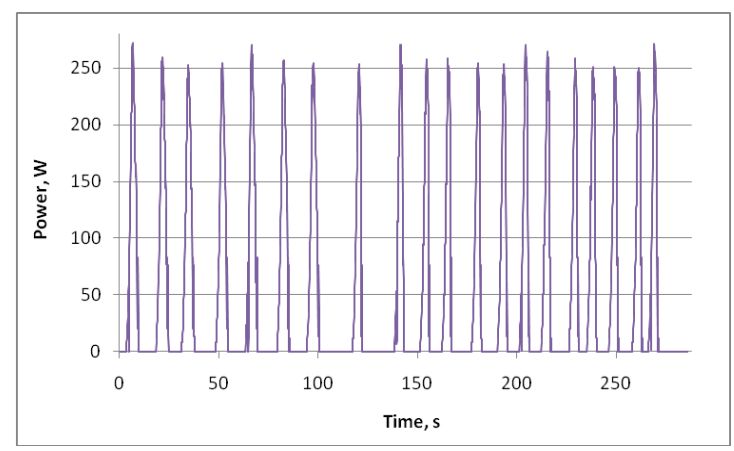

(b)

Figure 10. Experiment (a) without interference, (b) with interference.

Figure 10 (a) shows the system run without interference and Figure 10 (b) shows the system run with interference. Without interference, the system does not need to accelerate many times as the momentum before the car slows down is long, while if the system runs with interference, it needs threefold accelerations. This is due to the momentum of the car slowing down faster due to interference. Even though both systems have different quantities of acceleration, both systems finish within the time (288 s). This proves that the car will run at maximum efficiency for a fixed speed amplitude while still finishing within the given time.

\section{RESULTS AND DISCUSSION}

This section presents the actual results of the vehicle during the Shell Eco-marathon Asia 2014 held at Luneta Park, Manila. Based on 5 attempts allowed by the organizer, we had 3 valid attempts in which we managed to finish. The other 2 attempts were invalid due to mechanical problems with the vehicles. The racing schedule was set by the organizer with 3 attempts in the afternoon and the others in the morning. Figure 11(a) (b) and (c) present actual vehicle data for those 3 valid attempts.

On the first attempt, the average power usage was around $190 \mathrm{~W}$, as presented in Figure 11(a). Figure 11(b) shows the actual data for the second attempt, with average power of $154 \mathrm{~W}$. Figure 11(c) presents the data for the third attempt with an average power of approximately $205 \mathrm{~W}$. Many factors affect the performance of the vehicle even though the systems are designed to operate at an efficient point. Based on our observations and studies, the result for the first attempt is higher compared to the second, while the result of the third attempt is slightly higher compared with the first and second. On the first attempt, the vehicle ran in the afternoon when the temperature was around $42^{\circ} \mathrm{C}$. High temperature affects the performance of the vehicle and since all the electronics and the FC generate heat, the blower needs to operate regularly to supply the oxygen. On the third attempt, the vehicle ran in the evening when the temperature was around $43^{\circ} \mathrm{C}$ and there was an accident on the track and the car needed to stop for a few minutes. Since the distance needed to finish the race was longer while the time was shorter, the vehicle needed to accelerate faster to finish the race within the given time. One the second attempt, the vehicle ran early in the morning when there was little vehicle interference when the car was moving and the temperature was very good for 
FC working. Even though there was different energy usage for all attempts, the vehicle finished within the given time $(<24 \mathrm{~min})$.

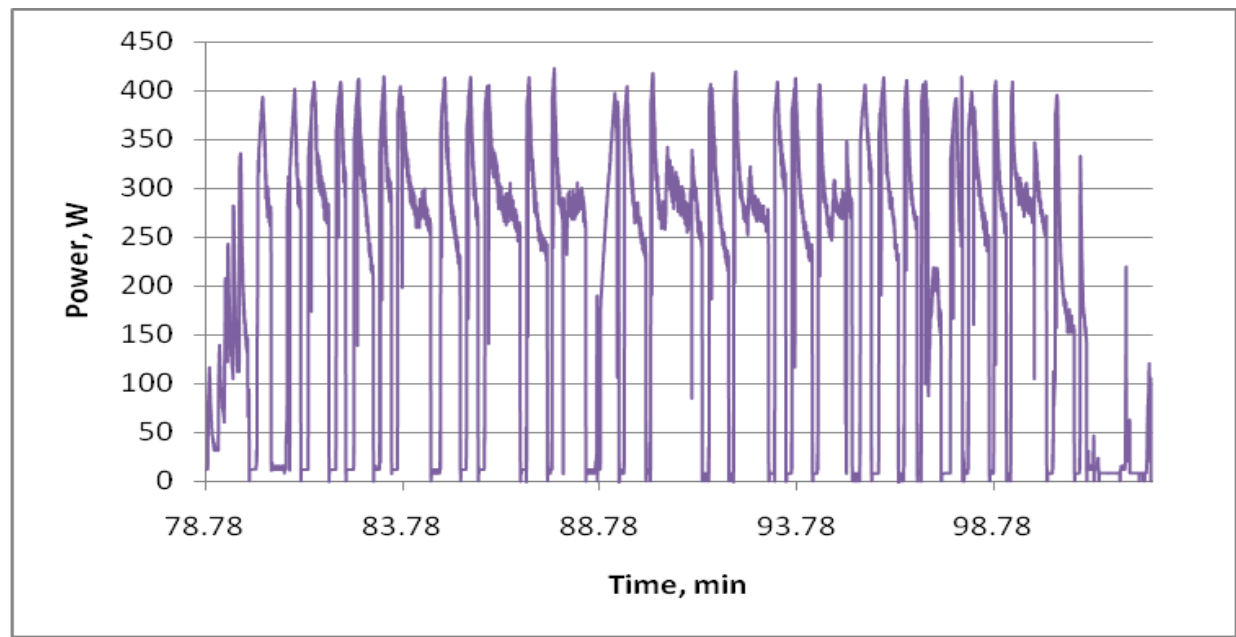

(a) Attempt no. 1

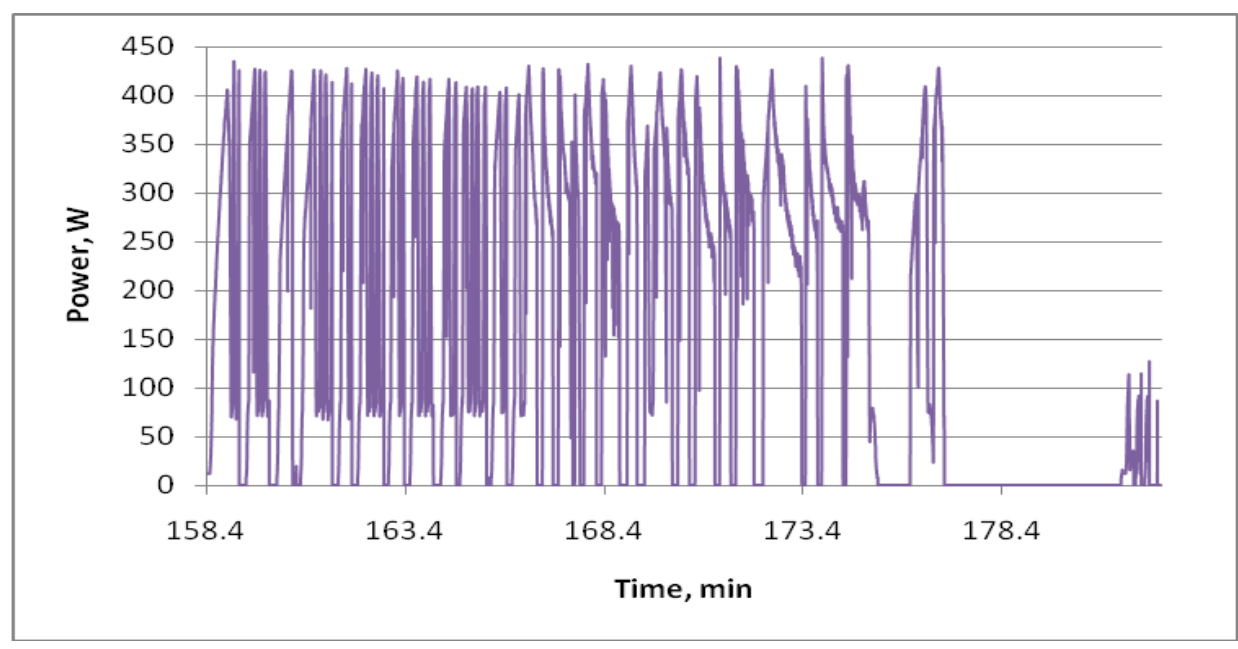

(b) Attemps no. 2

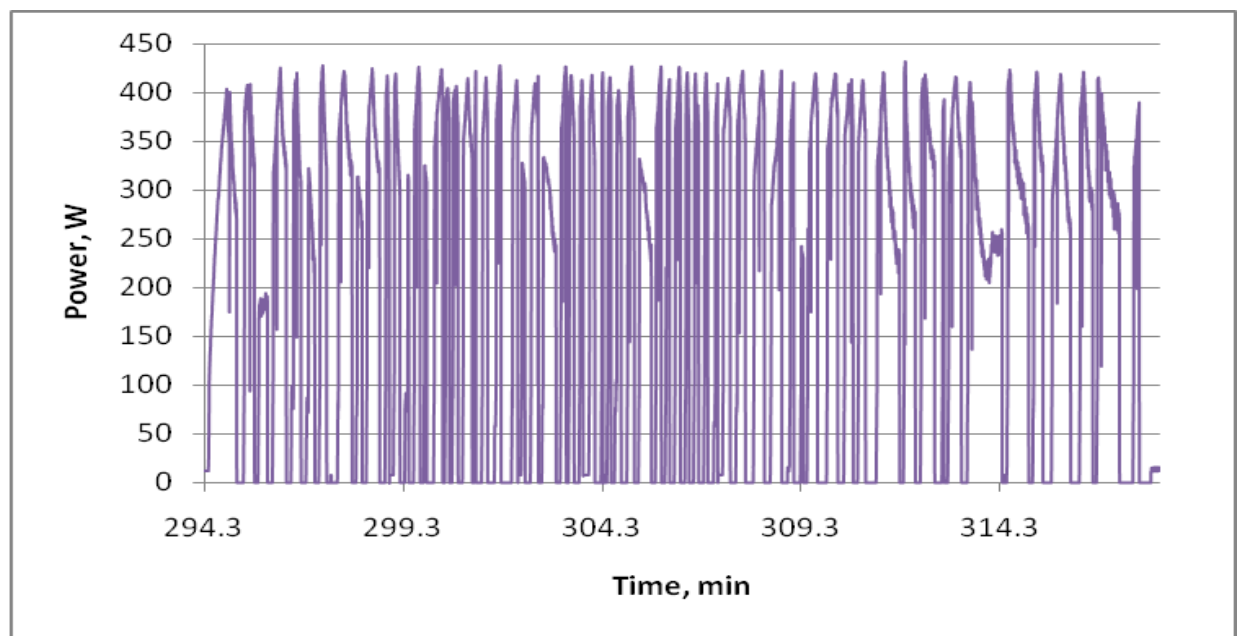

(c) Attempt no. 3

Figure 11. The average power usage. 


\section{CONCLUSIONS}

This paper presents a series of analyses to design, optimize and control the performance of a powertrain FC electric vehicle to be used in participating in energy-efficient races. Several experiments were conducted beforehand regarding controlling the vehicle, FC efficiency testing, vehicle dynamics modeling, track mapping analysis, DC motor characteristics and driving strategy techniques. These ensured the optimized sizing of the powertrain system for the vehicle and that the vehicle was controlled automatically to operate at maximum efficiency in each part of the powertrain system. This technique was applied to our vehicle and we won first place in the prototype FC category in the Shell Eco-marathon Asia 2014 race.

\section{ACKNOWLEDGEMENTS}

The authors gratefully acknowledge the financial support given for this work by the Universiti Teknologi MARA under the Faculty of Electrical Engineering, Faculty of Mechanical Engineering, Tabung Amanah HEP, Research Intensive Faculty Funds (600-RMI/DANA 5/3/RIF 867/2012) and our entire sponsor especially MyDuino.com and Commerce Dot Com (CDC) 2013/2014. Thousands of thanks to all academic/technical advisors from Universiti Teknologi MARA and also Universiti Malaya and last but not forget UiTM Eco-Sprint team members that have led to the construction of SperMotive-2 car.

\section{REFERENCES}

[1] Ahluwalia RK, Wang X. Direct hydrogen fuel cell systems for hybrid vehicles. Journal of Power Sources. 2005;139:152-64.

[2] Drolia A, Jose P, Mohan N. An approach to connect ultracapacitor to fuel cell powered electric vehicle and emulating fuel cell electrical characteristics using switched mode converter. 29th Annual Conference of the IEEE Industrial Electronics Society.2003;897-901.

[3] Rahmat MS, Ahmad F, Mat Yamin AK, Aparow VR, Tamaldin N. Modeling and torque tracking control of permanent magnet synchronous motor (PMSM) for hybrid electric vehicle. International Journal of Automotive and Mechanical Engineering. 2013;7:955-67.

[4] Salleh I, Md. Zain MZ, Raja Hamzah RI. Evaluation of annoyance and suitability of a back-up warning sound for electric vehicles. International Journal of Automotive and Mechanical Engineering. 2013;8:1267-77.

[5] Fletcher D, Haynes B, Christo F, Joseph S. A CFD based combustion model of an entrained flow biomass gasifier. Applied Mathematical Modelling. 2000;24:165-82.

[6] von Helmolt R, Eberle U. Fuel cell vehicles: Status 2007. Journal of Power Sources. 2007; 165:833-43.

[7] Corbo P, Migliardini F, Veneri O. PEFC stacks as power sources for hybrid propulsion systems. International Journal of Hydrogen Energy. 2009;34:463544.

[8] Pei P, Ouyang M, Lu Q, Huang H, Li X. Testing of an automotive fuel cell system. International Journal of Hydrogen Energy. 2004;29:1001-7. 
[9] Emadi A, Williamson SS, Khaligh A. Power electronics intensive solutions for advanced electric, hybrid electric, and fuel cell vehicular power systems. IEEE Transactions on Power Electronics. 2006;21:567-77.

[10] Larminie J, Lowry J. Electric vehicle technology explained: John Wiley \& Sons; 2004.

[11] Jain M, Desai C, Kharma N, Williamson SS. Optimal powertrain component sizing of a fuel cell plug-in hybrid electric vehicle using multi-objective genetic algorithm. 35th Annual Conference of IEEE Industrial Electronics. 2009;37416.

[12] Jeong KS, Oh BS. Fuel economy and life-cycle cost analysis of a fuel cell hybrid vehicle. Journal of Power Sources. 2002;105:58-65.

[13] Chan-Chiao L, Huei P, Grizzle JW, Jun-Mo K. Power management strategy for a parallel hybrid electric truck. IEEE Transactions on Control Systems Technology. 2003;11:839-49.

[14] Wang Y, Chen KS, Mishler J, Cho SC, Adroher XC. A review of polymer electrolyte membrane fuel cells: Technology, applications, and needs on fundamental research. Applied Energy. 2011;88:981-1007.

[15] Fakharuzi MHAM, Ward TA, Atan R. Performance analysis of different fuel cell lightweight vehicle power configurations while operating on an inclined road. 3rd International Conference on Fuel Cell \& Hydrogen Technology. Kuala Lumpur, Malaysia; 2011.

[16] Thounthong P, Chunkag V, Sethakul P, Davat B, Hinaje M. Comparative study of fuel-cell vehicle hybridization with battery or supercapacitor storage device. IEEE Transactions on Vehicular Technology. 2009;58:3892-904.

[17] Budzynski AF. Research on optimization of the process of electrochemical honing (ECH). International Symposium on Electromachining. 1983; 355-71.

[18] Ouyang M, Xu L, Li J, Lu L, Gao D, Xie Q. Performance comparison of two fuel cell hybrid buses with different powertrain and energy management strategies. Journal of Power Sources. 2006;163:467-79.

[19] Wolm P, Chen XQ, Chase JG, Pettigrew W, Hann CE. Analysis of a PM DC motor model for application in feedback design for electric powered mobility vehicles. 15th International Conference on Mechatronics and Machine Vision in Practice. 2008;640-5.

[20] Omar SMHS, Arshad NM, Fakharuzi MHAM, Ward TA. Development of an energy efficient driving strategy for a fuel cell vehicle over a fixed distance and average velocity. IEEE Conference on Systems, Process \& Control. 2013;11720. 